\title{
A National Laboratory: View from Within
}

\author{
Michael V. Nevitt
}

The late Norman Hilberry, an original member of the Manhattan Project team and director of Argonne National Laboratory in the late 1950s and early 1960s, prefaced an early long-range plan with the prediction that the Argonne Laboratory of the future would be somewhat of a compromise between what it aspired to be and what the scientific community and the nation were prepared to make it. Hilberry suspected that it might not always be easy for Argonne and the outside community to know what each expected of the other. And in this connection he foresaw two particularly large challenges:

1. Establishing at Argonne Laboratory a favorable balance between "big science" and "little science." (These terms weren't used then, but they were implicit in the discussion.)

2. Developing and maintaining mutually beneficial relationships between the Laboratory and industry and the universities.

Thirty years later, we can see that Norm had it right. Planning was difficult then and it still is. And the two challenges he cited are still central in the Laboratory's agenda-so much so that they can serve well as my discussion points.

I don't wish to claim that Argonne is such an appropriate model of the Department of Energy's national laboratories that my observations apply equally or evenly to the other laboratories. However, I am willing to assert that there is commonality and convergence in the challenges and goals in front of the national laboratories and in the ways they are responding to them.

Argonne National Laboratory is in good shape these days. Many lights are on these nights in labs and offices - always a clear sign of excitement and commitment. So what is happening now about the issues enumerated above?

There is growing competition - and some tension - between big science and little science within the Laboratory. This may come as a surprise to many who see a national laboratory as an embodiment of big science. In fact, Argonne and its sister multiprogram laboratories are home to a large number of teams doing coordinated energy research that involves lab-bench science as well as the use of accelerators, reactors, and other large machines. Materials preparation and characterization and materials research, fundamental and mission-oriented, represent a large part of the effort of these teams.

As more attention and more resources are directed to the introduction and support of large, laboratory-operated, user- dedicated facilities, a diminution of the effort of the smaller research teams seems inevitable. This decline, which already seems discernible in the materials research area, could mean the erosion of a singular resource, one that is unique to the national laboratories. While these teams are individualistic and self-contained in some respects, they quickly interact, unite and collaborate with each other and with external groups when a timely new research problem comes along. This kind of rapid response is now being demonstrated in a particularly visible way in the basic and applied work on the high $T_{c}$ oxide superconductors (the discovery of which, we must observe, had its origin in bench science, not big-machine science). In the research on these new materials there is a synergistic interplay between people doing laboratory-scale work (sample preparation, Meissner-effect measurements, Raman scattering, and heat capacity, for example) and people using the neutron and photon sources. The whole of this effort is greater than the sum of its parts and, as I see it, should be preserved.

I'll turn briefly now to Argonne National Laboratory's relationship to industry and to academe. Born of early Atomic Energy Commission guidelines and admonitions, a "church and state" separation arose to impair the Laboratory's interactions with industry in early years - nuclear power being a singular exception. These impediments, which showed up in such strictures as patent regulations and in policies regarding access to Laboratory facilities, are being dispelled at a measured pace. This seems to be a particularly fortunate and timely movement. There is agreement on all sides that the national laboratories have a special national role to play in improving the competitiveness of U.S. industry in transforming scientific findings into industrial innovations. The area of materials science is an especially crucial one in this respect.

Partnership with the scientists on the university campus has come in for much examination and introspection throughout the lifetime of Argonne National Laboratory. A discussion of this matter can have little substance unless it is admitted at the outset that, along with very much collaboration and cooperation, there is competition and rivalry between national laboratory science and university science. Perhaps as a means of simplifying a multidimensional issue, the competition has usually been expressed in dollar terms competition for research funding. This is certainly an important aspect of the matter, but there are other facets as well. We also compete for the best people, and they in turn compete to perform and publish the best research (often the highest $T_{c}$ 's nowadays), to gain the recognition of their peers, and to earn the best science awards and prizes. This competition has been altogether beneficial and stimulating to all contenders.

The scientific arena in which Argonne and the other national laboratories have only a few rivals is in the design, construction, and operation of major research facilities, where the resident talents, managerial resources, and continuity of effort are essential. I suppose there are people in the national laboratories and in the university community, and also in groups external to both, who would feel more comfortable if in the area of basic research the national laboratories had the operation of large user-dedicated facilities as their single, or almost single, raison d'etre, thereby reducing any perceived laboratory-university tensions and redundancies. But pushing on that notion brings us back full circle to the question of how much "little science" a national laboratory can afford to give up. To maintain excellence, a scientific establishment must have people doing first-class research, not just operating facilities - so there we are, back in the competitive mode. There will be much discussion and compromise regarding this issue. Norm Hilberry predicted that.

Michael $V$. Nevitt is a senior scientist at Argonne National Laboratory. A thirty-odd year veteran at Argonne, he was deputy director to two laboratory directors before rejoining a basic ceramics group to study phase transformations in oxides.

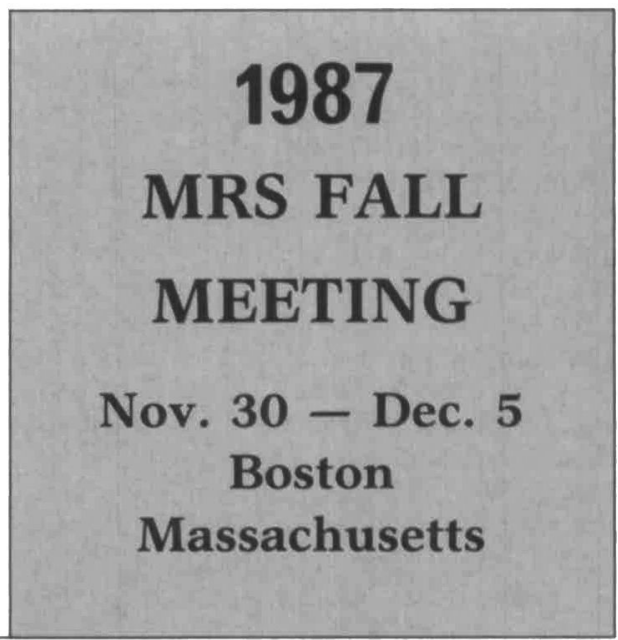

